\title{
Synthesis, crystal structure and magnetic properties of an alternating manganese chain
}

\author{
Manuela Ramos Silva ${ }^{\mathrm{a}, *}$, Ana Matos Beja ${ }^{\mathrm{a}}$, José António Paixão ${ }^{\mathrm{a}}$, Jesus Martín-Gil ${ }^{\mathrm{b}}$ \\ ${ }^{\text {a } C E M D R X, ~ D e p a r t a m e n t o ~ d e ~ F i ́ s i c a, ~ F a c u l d a d e ~ d e ~ C i e ̂ n c i a s ~ e ~ T e c n o l o g i a, ~ U n i v e r s i d a d e ~ d e ~ C o i m b r a, ~ P-3004-516 ~ C O I M B R A, ~ P o r t u g a l ~}$ \\ ${ }^{\mathrm{b}}$ ETSIA, Universidad de Vallodolid, Avda Madrid 57, 34004 Palencia, Spain
}

Received 2 February 2006; received in revised form 15 March 2006; accepted 17 March 2006

Available online 28 March 2006

\begin{abstract}
A new 1D complex has been prepared and characterized. X-ray single crystal structure confirms that the Mn(II) ions assemble in alternating chains with Mn-Mn distances of 3.8432(13) and 4.4428(14) A. A 3D network of hydrogen bonds links the chains together. The temperature dependence of the magnetic susceptibility reveals that this compound undergoes a magnetic transition and exhibits an antiferromagnetic interaction in the low-temperature phase with two alternating exchange interactions of $-2.32(1)$ and $-5.55(1) \mathrm{cm}^{-1}$.
\end{abstract}

(C) 2006 Elsevier Inc. All rights reserved.

Keywords: Mn(ii) complexes; Dimethylglycine; X-ray structure; Antiferromagnetic interaction

\section{Introduction}

The study of paramagnetic manganese carboxylate clusters was given a boost since the discovery that some molecules can behave as nanoscale magnets [1]. At low enough temperatures, those molecules display a magnetization versus applied field hysteresis loops associated with a slow magnetization relaxation. Their properties derive from the combination of a large ground-spin $(S)$ value and a significant magnetoanisotropy of the Ising (easy-axis) type. Many applications of these single-molecule magnets (SMMs) are devised, such as in high-density information storage, where each bit of information would be stored on a single molecule, and in quantum computing, where each molecule would function as a quantum bit. Of the SMMs known to date, the archetypal $\mathrm{Mn}_{12}$ family constitutes the most famous and studied example with $\left[\mathrm{Mn}_{12} \mathrm{O}_{12}\left(\mathrm{O}_{2} \mathrm{CR}\right)_{16}\right.$ $\left.\left(\mathrm{H}_{2} \mathrm{O}\right)_{4}\right)$ ] exhibiting SMM behaviour at the highest temperature (ca. $6 \mathrm{~K}$ ) [2].

\footnotetext{
${ }^{*}$ Corresponding author.

E-mail address: manuela@pollux.fis.uc.pt (M. Ramos Silva).
}

SMM behaviour has been found not only in cluster type compounds but also in ID chains. Tetranuclear manganese units $\left(\mathrm{Mn}_{4}(\mathrm{hmp})_{6}\right)$ bridged by chloride ions [3] or chains of ferromagnetic coupled $\mathrm{Mn}(\mathrm{III})-\mathrm{Ni}(\mathrm{II})-\mathrm{Mn}$ (III) units [4], have shown slow magnetization relaxation.

Carboxylate-bridged complexes have shown to be versatile, both in the bridging coordination modes of the carboxylate and in the resulting magnetic properties. A loose correlation has even been found between the type and number of bridging mode and the magnetic interactions. Durot et al. [5] report that in $\mathrm{Mn}$ (II) complexes the magnitude of the antiferromagnetic coupling mediated through carboxylato bridges $(|\boldsymbol{J}|)$ increases with the number of bridges, with the syn-syn triatomic mode (-OCO-) being the more efficient pathway. $|J|$ values for halogenato $\mathrm{Mn}$ (II) chains are usually higher [5].

In this paper we describe the synthesis of a dimethylglycine and chloride-bridged $\mathrm{Mn}(\mathrm{II})$ compound with an antiferromagnetic alignment of the metallic spins, below $23 \mathrm{~K}$. We have essayed the synthesis of compounds with dimethylglycine and manganese driven by the success in obtaining lowdimensional compounds with trimethylglycine and manganese, namely chains [6,7] and SMMs clusters [8]. 


\section{Experimental}

2.1. Synthesis of catena triaquatricloro- $\mu_{2}-$ (bis $(N$-dimethylglycine- $\left.O, O^{\prime}\right)$ ) dimanganese (II) chloride monohydrated

$0.88 \mathrm{~g}$ of dimethylglycine were added to $1.76 \mathrm{~g}$ of hydrated manganese chloride in a water solution $(2 \mathrm{~mL})$. After a few months at room temperature and pressure small single crystals were grown, with a pale pink colour.

\subsection{X-ray structure determination}

A single crystal with dimensions $0.24 \times 0.18 \times 0.07 \mathrm{~mm}^{3}$ was used for structural determination at $293 \mathrm{~K}$ on an Enraf-Nonius diffractometer with a point detector and graphite-monochromated MoK $\alpha$ radiation. All computations were carried out on a PC-586 computer running Linux. Number of measured, unique, and observed reflections $[I>2 \sigma(I)]$ are 3782,3501 and $2710\left(R_{\text {int }}=2.52\right)$. The structure was solved by direct methods using SHELXS97 [9] and refined on $F^{2}$ by full-matrix leastsquares methods using SHELXL97 [9]. All the nonhydrogen atoms were refined anisotropically. Hydrogen atoms were constrained to ride on the respective parent atoms with an isotropic displacement parameter multiple of that of the parent atom using SHELXL97 defaults. Crystal data are summarized in Table 1. Selected bond lengths and bond angles are listed in Table 2. H-bond geometry is listed in Table 3 .

\subsection{Magnetic measurements}

Magnetic data on crushed single crystals were collected using a Quantum-Design MQMS superconducting

Table 1

Crystallographic data

\begin{tabular}{ll}
\hline Formula & $\mathrm{C} 8 \mathrm{H} 26 \mathrm{Cl} 4 \mathrm{Mn} 2 \mathrm{~N} 2 \mathrm{O} 18$ \\
$\mathrm{M}$ & 529.99 \\
Crystal System & Monoclinic \\
Space Group & $P 2_{1} / c$ \\
$a(\AA)$ & $7.5801(19)$ \\
$b(\AA)$ & $16.324(5)$ \\
$c(\AA)$ & $16.857(4)$ \\
$\beta(\mathrm{deg})$ & $106.21(3)$ \\
$V\left(\AA^{3}\right)$ & $2002.9(10)$ \\
$\mathrm{Z}$ & 4 \\
$\left.D_{\mathrm{c}}(\mathrm{g} \mathrm{cm})^{-3}\right)$ & 1.758 \\
$F(000)$ & 1080 \\
$\mathrm{Goodness}-\mathrm{of}-\mathrm{fit}$ on $F^{2}$ & 1.089 \\
$R_{1}, \mathrm{w} R_{2}[\mathrm{I}>2 \sigma(\mathrm{I})]^{\mathrm{a}}$ & $0.0233,0.0639$ \\
$(\mathrm{All}$ data) & $0.0491,0.0576$ \\
$(\Delta \rho)_{\min },(\Delta \rho)_{\max }\left(\mathrm{e}^{-} \AA^{-3}\right)$ & $-0.317,0.410$ \\
\hline
\end{tabular}

\footnotetext{
${ }^{\mathrm{a}} R_{1}=\Sigma|| F_{0}|-| F_{\mathrm{c}}|| / \Sigma\left|F_{0}\right|, \quad \mathrm{w}=1 /\left[\sigma^{2}\left(F_{0}^{2}\right)+(0.0278 P)^{2}+1.4570 P\right]$ where
} $P=\left(F_{0}^{2}+2 F_{\mathrm{c}}^{2}\right) / 3$.
Table 2

Selected geometrical parameters

Bond distances $(\AA)$

\begin{tabular}{ll}
\hline $\mathrm{O} 1-\mathrm{C} 1$ & $1.258(3)$ \\
$\mathrm{N} 1-\mathrm{C} 4$ & $1.485(4)$ \\
$\mathrm{N} 1-\mathrm{C} 2$ & $1.485(3)$ \\
$\mathrm{N} 1-\mathrm{C} 3$ & $1.493(4)$ \\
$\mathrm{O} 2-\mathrm{C} 1$ & $1.240(3)$ \\
$\mathrm{O} 3-\mathrm{C} 5$ & $1.241(3)$ \\
$\mathrm{O} 4-\mathrm{C} 5$ & $1.249(3)$ \\
$\mathrm{N} 2-\mathrm{C} 7$ & $1.477(3)$ \\
$\mathrm{N} 2-\mathrm{C} 6$ & $1.478(3)$ \\
$\mathrm{N} 2-\mathrm{C} 8$ & $1.484(3)$ \\
$\mathrm{C} 1-\mathrm{C} 2$ & $1.515(3)$ \\
$\mathrm{C} 5-\mathrm{C} 6$ & $1.515(3)$
\end{tabular}

\section{Bond angles (deg)}

$\mathrm{Mn} 1-\mathrm{Cl1}-\mathrm{Mn} 2$

$\mathrm{Mn} 1-\mathrm{Cl} 2-\mathrm{Mn} 2$

$\mathrm{O} 2-\mathrm{C} 1-\mathrm{O} 1$

O3-C5-O4 127.2(2)

$\begin{array}{lr}\text { Torsion angles }(\mathrm{deg}) & \\ \text { C8-N2-C6-C5 } & -165.0(2) \\ \mathrm{C} 7-\mathrm{N} 2-\mathrm{C} 6-\mathrm{C} 5 & 71.4(3) \\ \mathrm{C} 3-\mathrm{N} 1-\mathrm{C} 2-\mathrm{C} 1 & 77.2(3) \\ \mathrm{C} 4-\mathrm{N} 1-\mathrm{C} 2-\mathrm{C} 1 & -158.4(3) \\ \mathrm{O} 2-\mathrm{C} 1-\mathrm{C} 2-\mathrm{N} 1 & 10.9(3) \\ \mathrm{O} 1-\mathrm{C} 1-\mathrm{C} 2-\mathrm{N} 1 & -171.0(2) \\ \mathrm{N} 2-\mathrm{C} 6-\mathrm{C} 5-\mathrm{O} 3 & 27.6(3) \\ \mathrm{N} 2-\mathrm{C} 6-\mathrm{C} 5-\mathrm{O} 4 & -154.0(2)\end{array}$

Table 3

H-bond parameters

\begin{tabular}{lllll}
\hline Atoms & $\mathrm{D}-\mathrm{H}$ & $\mathrm{H} \cdots \mathrm{A}$ & $\mathrm{D}-\mathrm{H} \cdots \mathrm{A}$ & Angles \\
\hline $\mathrm{O} 6-\mathrm{H} 61 \ldots \mathrm{O} 1^{\mathrm{i}}$ & $0.84(4)$ & $1.93(4)$ & $2.769(3)$ & $176(3)$ \\
$\mathrm{O} 6-\mathrm{H} 62 \ldots \mathrm{O} 4$ & $0.79(4)$ & $2.47(4)$ & $2.872(3)$ & $113(3)$ \\
O6-H62 $\ldots \mathrm{Cl} 4^{\text {ii }}$ & $0.79(4)$ & $2.62(4)$ & $3.344(2)$ & $153(3)$ \\
$\mathrm{O} 7-\mathrm{H} 71 \ldots \mathrm{Cl} 4$ & $0.82(4)$ & $2.41(4)$ & $3.224(2)$ & $178(3)$ \\
$\mathrm{O} 7-\mathrm{H} 72 \ldots \mathrm{O} 4^{\mathrm{iii}}$ & $0.74(4)$ & $2.05(4)$ & $2.774(3)$ & $171(4)$ \\
$\mathrm{O} 8-\mathrm{H} 81 \ldots 6^{\text {iv }}$ & $0.88(5)$ & $2.26(5)$ & $2.943(4)$ & $135(4)$ \\
$\mathrm{O} 8-\mathrm{H} 82 \ldots \mathrm{Cl} 2^{\mathrm{v}}$ & $0.89(5)$ & $2.43(5)$ & $3.278(3)$ & $159(4)$ \\
$\mathrm{O} 5-\mathrm{H} 51 \ldots \mathrm{Cl} 3^{\text {vi }}$ & $0.80(4)$ & $2.36(4)$ & $3.144(2)$ & $167(4)$ \\
$\mathrm{O} 5-\mathrm{H} 52 \ldots \mathrm{Cl} 4^{\text {vi }}$ & $0.86(4)$ & $2.27(4)$ & $3.119(2)$ & $169(3)$ \\
$\mathrm{N} 1-\mathrm{H} 1 \ldots \mathrm{O} 8^{\text {vii }}$ & $0.86(3)$ & $1.95(3)$ & $2.748(4)$ & $155(3)$ \\
$\mathrm{N} 2-\mathrm{H} 2 \ldots \mathrm{Cl} 4$ & $0.88(3)$ & $2.39(3)$ & $3.181(2)$ & $150(2)$ \\
\hline
\end{tabular}

i: $x+1, y, z$; ii: $-x,-y,-z+1$; iii: $x-1, y, z$; iv: $x-1,-y+3 / 2, z-1 / 2$; v: $-x,-y+1,-z$; vi: $x+1,-y+3 / 2, z+3 / 2$; vii: $1+x, 1 / 2-y, 1 / 2+z$.

quantum interference device (SQUID) magnetometer. Susceptibility curves were measured over the temperature range $2-250 \mathrm{~K}$, after field cooling $(100 \mathrm{Oe})$ and zero-field cooling. Magnetization data was recorded at several temperatures using magnetic fields from 0 to $5.5 \mathrm{~T}$. 


\section{Results and discussion}

\subsection{Crystal structure}

The metallic atoms are assembled in infinite chains of dimers running along the $a$-axis. Each dimeric unit contains two crystalographically independent $\mathrm{Mn}(\mathrm{II})$ ions bridged by the carboxylic groups of two organic moieties and one chloride ion (Fig. 1). A distinct chloride ion links the dimers into chains (Fig. 2). Both metallic ions have approximated octahedral geometries.

Mn1 is surrounded by two carboxylic oxygen atoms, 1 water oxygen and 3 chloride ions, with the $\mathrm{Cl}^{-}$ions being

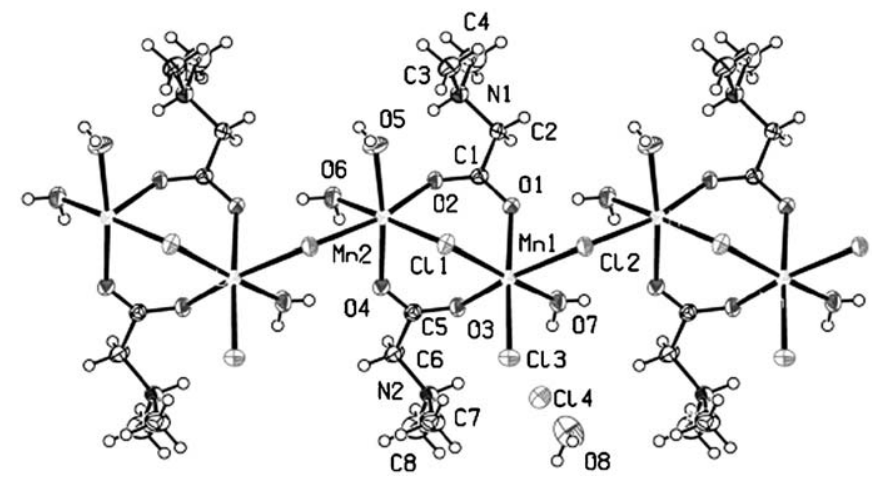

Fig. 1. Ortep diagram of the title compound. Ellipsoids are drawn at the $50 \%$ probability level.

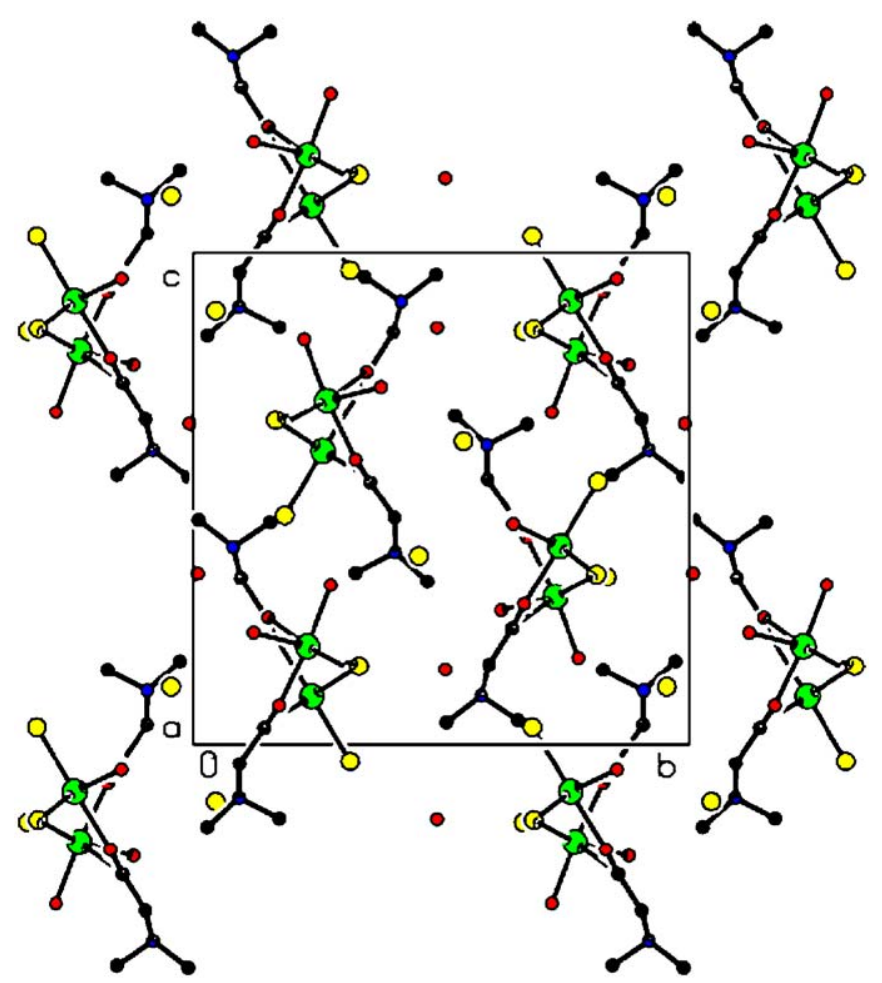

Fig. 2. Two of the infinite chains that run along the $a$-axis. Hydrogen atoms were omitted for clarity. mutually cis, $\mathrm{Cl}-\mathrm{Mn} 1-\mathrm{Cl}$ angles ranging from $91.79(4)^{\circ}$ to $97.07(3)^{\circ}$.

$\mathrm{Mn} 2$ is coordinated by 2 carboxylic oxygen atoms, 2 water oxygen atoms, and 2 chloride ions, with Cl1-Mn2$\mathrm{Cl} 2$ angle of $96.29(3)^{\circ}$.

The inner-dimer bridging angle, $\mathrm{Mn} 1-\mathrm{Cl} 1-\mathrm{Mn} 2$, is $99.22(4)^{\circ}$. Along the chain, $\mathrm{Mn} 1$ has two nearest Mn2 neighbours at distances 3.8432(13) and 4.4428(14) $\AA$. The outer-dimer bridging angle, $\mathrm{Mn} 1-\mathrm{Cl} 2-\mathrm{Mn} 2^{i}$, is $119.57(3)^{\circ}$ $(i:-1+x, y, z)$.

The organic moieties (substituted glycine molecules) are present in the neutral, dipolar, zwitterionic form. Inspection of the $\mathrm{C}-\mathrm{O}$ distances in the carboxylic groups show that these groups are deprotonated. Carboxylic groups are rotated about $10^{\circ}\left[26^{\circ}\right]$ around $\mathrm{C} 1-\mathrm{C} 2$ and $\mathrm{C} 5-\mathrm{C} 6$, respectively. Chains are interconnected through hydrogen bridges in a complex 3D network of H-bonds (Fig. 3). Each chain establishes hydrogen bridges with 5 other chains. $\mathrm{Cl} 4$ ion accepts protons donated by 3 neighbouring chains. The isolated water molecule shares its hydrogen atoms with another water oxygen $(\mathrm{O} 6)$ and a chloride ion $(\mathrm{Cl} 2)$ of the near chains and accepts another from the amino group of one of the substituted aminoacids, N1.

The formation of chains is also seen in a similar compound, catena diaqua-dichloro- $\mu_{2}$-(methylglycine$\mathrm{O}, \mathrm{O}^{\prime}$ ) manganese (II), previously reported by us [10]. In this case a similar synthetic procedure led to the formation of uniform zig-zag chains with the metal atoms solely bridged by the organic moieties.

\subsection{Magnetic properties}

The temperature dependence of the magnetic susceptibility of catena triaquatricloro- $\mu_{2}-\left(\operatorname{bis}\left(N\right.\right.$-dimethylglycine- $\left.\left.\mathrm{O}, \mathrm{O}^{\prime}\right)\right)$

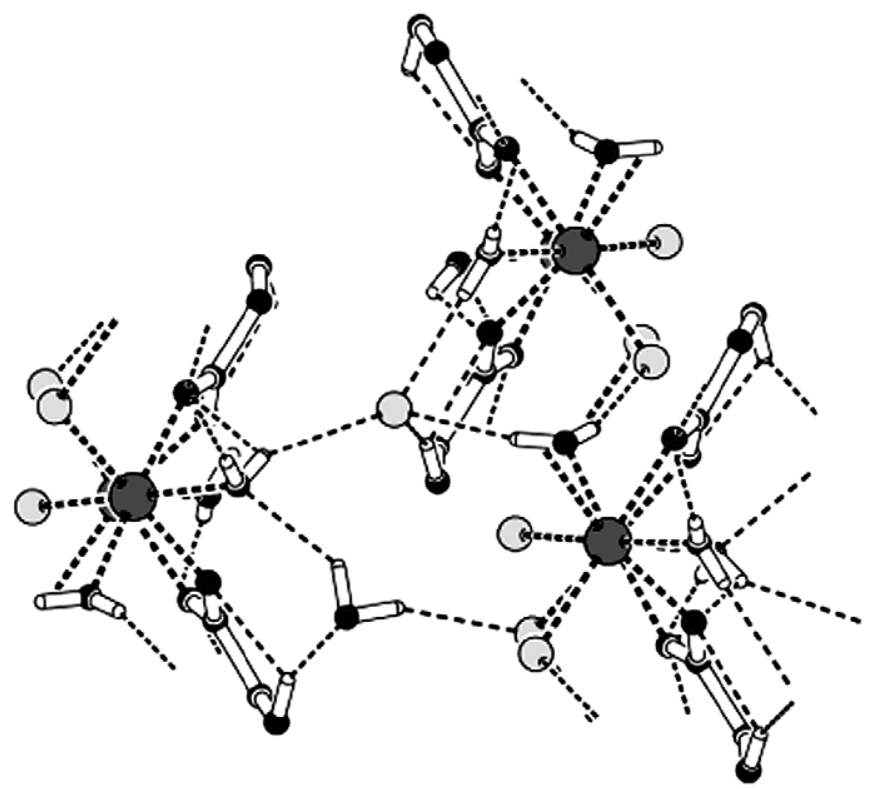

Fig. 3. H-bonding network. H-bonds are drawn in light-dashed lines. 
dimanganese(II) chloride monohydrated was measured under an applied field of $100 \mathrm{Oe}$ in the temperature range 2-250 K, both in the field-cooled and zero field-cooled regime, with very similar results.

The plot of the molar susceptibility versus $T$ is shown in Fig. 4. The overall magnetic behaviour corresponds to an antiferromagnetic-coupled system. The increasing of the susceptibility at very low temperatures is attributed to the presence of impurities. Fig. 5 plots $\chi^{-1}$ versus $T$. Upon cooling down the sample, $\chi^{-1}$ linearly decreases until $50 \mathrm{~K}$, as expected for a paramagnetic behaviour. The hightemperature range $(T>50 \mathrm{~K})$ can be well fitted by the equation $\chi=(C / T-\theta)+$ TIP with the fitting parameters being $C=9.32(5) \mathrm{cm}^{3} \mathrm{~K} \mathrm{~mol}^{-1}, \quad \theta=-52.5(4) \mathrm{K}$ and TIP $=6(2) \times 10^{-4} \mathrm{~cm}^{3} \mathrm{~mol}^{-1}$.

A least-squares fitting of the Cortés expansion [11]:

$\chi=\frac{N g^{2} \mu_{B}^{2}}{3 k T}\left(\frac{1+u_{1}+u_{2}+u_{1} u_{2}}{1-u_{1} u_{2}}\right)$

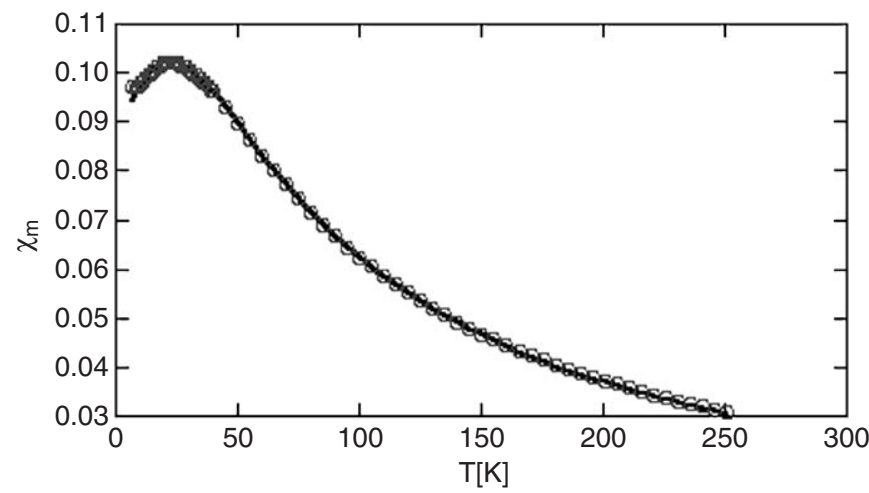

Fig. 4. Open circles represent the magnetic susceptibility experimental values. The solid black line represent the theoretical Cortés fit as explained in the text.

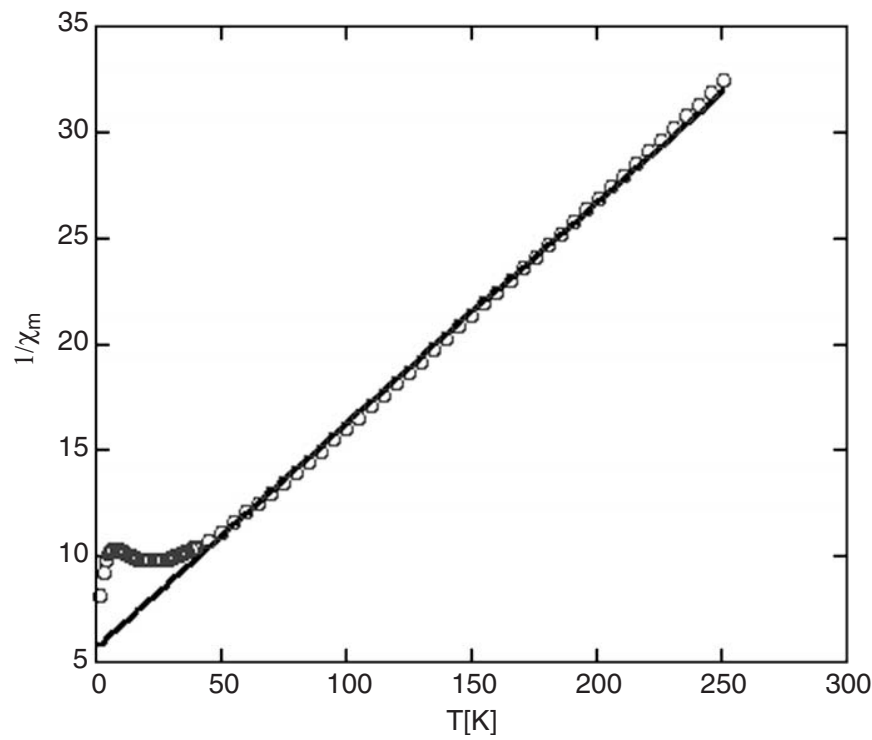

Fig. 5. Thermal variation of the inverted magnetic susceptibility $\left(\mathrm{cm}^{-3} \mathrm{~mol}\right)$. The solid line is a fit of the paramagnetic region using the Curie-Weiss model.

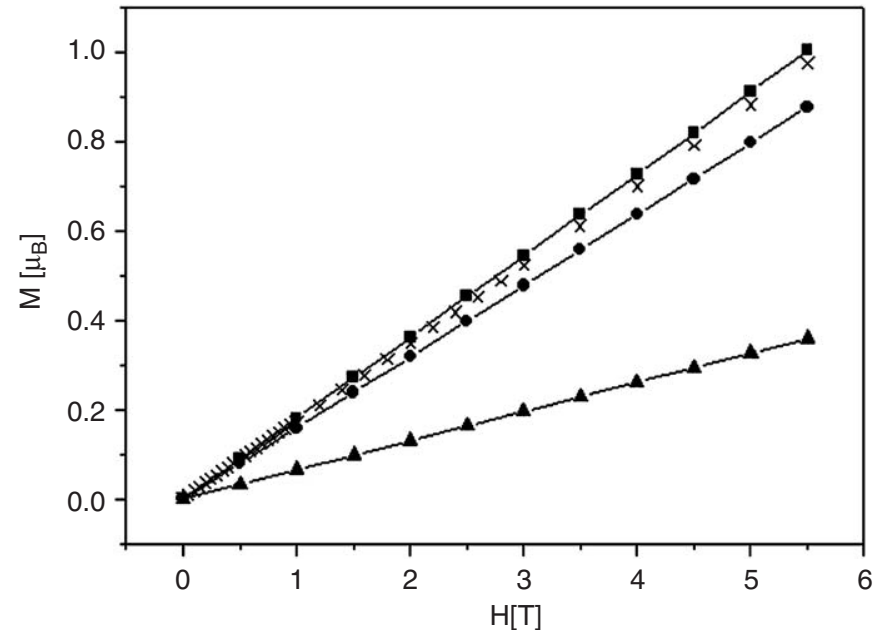

Fig. 6. Magnetization $\left(\mu_{\mathrm{B}}\right)$ curves versus applied magnetic field $(T)$ at $10 \mathrm{~K}$ $(x), 25 \mathrm{~K}(\mathbf{\square}), 50 \mathrm{~K}(\bullet)$ and $200 \mathrm{~K}(\mathbf{\Delta})$.

with $\left(\operatorname{coth}\left(J_{p} / k T\right)-k T / J_{p}\right)=\mu_{p}$, returned as best parameters $J_{1}=-2.32(1) \mathrm{cm}^{-1}, J_{2}=-5.55(1) \mathrm{cm}^{-1}$ and $g=$ $2.000(2)$. The fitting was performed in the $7-250 \mathrm{~K}$ region, and fits the data perfectly. The theoretical curve is represented by a solid line in Fig. 4.

Fig. 6 shows the magnetization curves measured at 10 , 25,50 and $200 \mathrm{~K}$ with the applied magnetic field ranging from 0 to $5.5 \mathrm{~T}$. The linear dependence of the magnetization of the sample with the applied field is characteristic of an antiferromagnetic interaction.

\section{Supplementary materials}

Crystallographic data for structural analysis have been deposited with the Cambridge Crystallographic Data Center, CCDC No. 297113. Copies of this information may be obtained free of charge on application to CCDC, 12 Union Road, Cambridge CB2 1EZ, UK (fax: + 441223 336 033; e-mail: deposit@ccdc.cam.ac.uk or http://www. ccdc.cam.ac.uk).

\section{Acknowledgments}

This work was supported by Fundação para a Ciência e a Tecnologia under project POCI/FIS/57876/2004. The authors are indebted to Prof. Margarida Godinho for the use of the SQUID magnetometer.

\section{Appendix A. Supplementary materials}

Supplementary data associated with this article can be found in the online version at doi:10.1016/j.jssc.2006. 03.024 . 


\section{References}

[1] R. Sessoli, D. Gatteshi, A. Caneshi, M. Novak, Nature 365 (1993) 149.

[2] P. Gerbier, D. Ruiz-Molina, N. Domingo, D.B. Amabilino, J. VidalGancedo, J. Tejada, D.N. Hendrickson, J. Veciana, in: W. Linert, M. Verdaguer (Eds.), Molecular Magnets Recent Highlights, Springer, New York, 2003, p. 149.

[3] J. Yoo, W. Wernsdorfer, E.C. Yang, M. Nakano, A.L. Rheingold, D.N. Hendricson, Inorg. Chem. 44 (2005) 3377.

[4] C. Coulon, R. Clérac, L. Lecren, W. Wernsdorfer, H. Miyasaka, Phys. Rev. B 69 (2004) 132408.

[5] S. Durot, C. Policar, G. Pelosi, F. Bisceglie, T. Mallah, J.-P. Mahy, Inorg. Chem. 42 (2003) 8072.
[6] L. Wiehl, J. Schereuer, E. Haussuhl, Z. Kristallogr. NCS 221 (2006) 1.

[7] X.M. Chen, T.C.W. Mak, Inorg. Chim. Acta 189 (1991) 3.

[8] E. Coronado, A. Formet-Aliaga, A. Gaita-Arino, C. Jiménez-Saiz, F.M. Romero, W. Wernsdorfer, Angew. Chem. Int. Ed. 43 (2004) 6152.

[9] G.M. Sheldrick, SHELXS97 and SHELXL-97, Univ. of Gottingen, Germany, 1997.

[10] M. Ramos Silva, A. Matos Beja, J.A. Paixão, L. Alte da Veiga, Z. Kristallogr. NCS 216 (2001) 419.

[11] R. Cortés, M. Drillon, X. Solans, L. Lezama, T. Rojo, Inorg. Chem. 36 (1997) 677. 